http://jmscr.igmpublication.org/home/

ISSN (e)-2347-176x ISSN (p) 2455-0450

crossref DOI: https://dx.doi.org/10.18535/jmscr/v7i7.143

\title{
Comparative study of anti-inflammatory effect of diclofenac and aceclofenac on human
}

\author{
Author \\ Dr Amit Kumar Jha \\ Associate Professor, Department of Pharmacology Vardhman, Institute of Medical Sciences, \\ Pawapuri (Nalanda) Bihar \\ Corresponding Author \\ Dr Amit Kumar Jha \\ Associate Professor, Department of Pharmacology VIMS, Pawapuri, Bihar, India
}

\begin{abstract}
Various exogenous and endogenous stimuli incite a complex reaction in vascularized connective tissue called inflammation. Non steroidal anti inflammatory drugs are used to reduce inflammation. Preferential COX-2 inhibitors namely diclofenac and aceclofenac was taken for my present work and anti inflammatory effect was compared with control and with each other. Student-t-test-was done to compare result. It was found that inflammation varied significantly across the three groups $(P=.000)$ Compared to control, inflammation was less in both diclofenac and aceclofenac $(P=.00)$. Reduction of inflammation with diclofenac was less. In comparision to aceclofenac at end. Aceclofenac is more efficacious than diclofenac.

Keywords: Aceclofenac, diclofenac, Anti inflammatory effect.
\end{abstract}

\section{Introduction}

The inflammation dilutes, destroyes or isolates the causation agent and sets into motion the sequence of event that heal and reconstitute the damaged tissue. ${ }^{1}$

Aceclofenac is moderately $\mathrm{COX}-2$ selective congener of diclofenac having similar property and may confer condroprotective. ${ }^{2}$

The basic morphologic patterns, which frequently have clinical significance are (serous, fibrinous, suppurative) inflammation along with ulceration. Aceclofenac is more gastric - friendly as it is somewhat -Cox-2 Selective and is also longer acting. ${ }^{3}$

\section{Materials and Methods}

This work was done at the department of pharmacology of vardhman Institute of Medical science, of pawapuri Bihar. Regarding ethical aspect, I had informed concerned authority of this college. The patients were grouped as control, diclofenac, aceclofenac for induction of inflammation. For studying anti-inflammatory effect urate induced synovitis method of Mc carty et.al was adopted. ${ }^{4}$

Prepration of sodium urate crystal. 4gm sodium hydroxide pellet were dissolved in $400 \mathrm{ml}$ distilled water in a glass beaker. $1.68 \mathrm{gm}$ uric Acid was added. The resultant opaque prepration was allowed to remain over night at room temperature. 
The next morning the crystals were harvested by decanting the supernatant solution and were then washed, 3times in cold saline resuspended in saline and sterilized in an autoclave. Weight of aceclofenac and diclofenac taken during experiment was $100 \mathrm{mg}$ and $50 \mathrm{mg}$ respectively. Suspensions for injection were kept in rubberstoppered multi-does vial containing 15 to $24 \mathrm{mg}$ urate per ml. Men weighing between 50 to $60 \mathrm{~kg}$. were taken. The skin above one knee was disinfected and a sterile 21 gauge needle was inserted into the joint. Slight aspiration produced a small amount of clear viscous synovial fluid indicating entry into joint. The needle was left in place, a syringe containing the urate suspension was attached and volume from. 1 to $5 \mathrm{ml}$ was injected into the joint (approximately 2 to $\mathrm{mg}$ urate). One hour before the injection of urate crystal. Men were treated with test compound or the standard. Experiment was designed so that 5 pair of men was tested on each of 2days. On the first day only one pair men received the drug one week later the opposite knee of each pair of man was injected but the other pair of men was Treated.

Statistical Analysis: Scoring system was adopted in which inflammatory symptom ranging from tenderness limping was assessed. Data was presented in (Mean \pm SEM ) and were analysed using statistical package in for social scientist 10 (SPSS) student's t-test and ANOVA were applied to compare significance between different groups $(\mathrm{p}<0.05){ }^{5}$

\section{Results and Discussion}

(Edema) With control diclofenac and aceclofenac

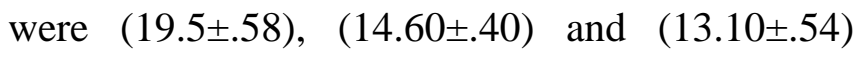
respectively four hour after drug administration. The mean edema in three groups varied significantly $[\mathrm{F}(2,27)=140.48, \mathrm{P}=.000]$ the mean edema of acelofenac group was significantly less than control [t $(18)=8.14, p=.000]$.It was also significantly less in diclofenac group in comparison to control $[\mathrm{t}(18)=6.44 \quad \mathrm{P}=.000]$ However the mean swelling in aceclofenac group was found less in comparision to aceclofenac group [ $\mathrm{t}(18=2.58 \mathrm{P}=.018]$ sehgal $\mathrm{A}$ et al in year 2015 conducted antiinflammatory work and found after 8 week that swelling reduction with aceclofenac was from $9.16 \pm .03$ to $4.88 \pm .79$ and

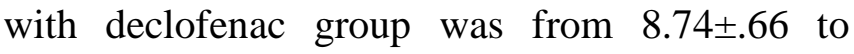
$5.87 \pm .92{ }^{6}$ It became significant that Aceclofenac reduced the swelling more than diclofenac group .

\section{Conclusion}

From above observation it is evident that aceclofenac is more efficacious than diclofenac as far as anti-inflammatory effect is concerned.

\section{References}

1. Kumar Cotran Robbins, Acute and chronic inflammation Basic pathology. Elsevier $6^{\text {th }}$ edition 1997, 25-46.

2. Tripathi KD.Non steroidal anti inflammatory Drugs and AntipyreticsAnalgesics. Essential of medical pharmacology. Jaypee $7^{\text {th }}$ edition New Delhi 2014, 192-209.

3. Uday kumar padmaja Non steroidal anti inflammatory drugs (NSAIDS). Medical pharmacology CBC publishers and distributors Pvt Ltd. Revised $4^{\text {th }}$ edition New Delhi; 2013 251-263.

4. Gupta Sk Analgesic Agents. Drug screening methods. The health science publisher. $3^{\text {rd }}$ edition New Delhi 2016. 476-494.

5. Mahajan Bk significence of difference in mean methods in Biostatistics jaypee $7^{\text {th }}$ edition New Delhi; 2010 117-141

6. Sehgal A et. Al comparision of efficacy and tolerability of aceclofenac and diclofenac in osteoarthritis of knee joint IJMDS July 2015; (2). 